\title{
A corpus-based analysis: The types of transition markers in the MA theses of native speakers of English and Turkish speakers of English
}

\author{
Zehra Köroğlu $\mathrm{a}^{\text {*iD }}$ \\ ${ }^{a}$ Çağ University, Yenice, Tarsus, Mersin, Turkey
}

\author{
APA Citation: \\ Köroğlu, Z. (2019). A corpus-based analysis: The types of transition markers in the MA theses of native speakers of English and Turkish \\ speakers of English. Journal of Language and Linguistic Studies, 15(2), 496-507. \\ Submission Date:06/10/2018 \\ Acceptance Date:03/12/2018
}

\begin{abstract}
This study has been conducted to evaluate transition marker (TM) types in the MA theses written by the native speakers (NSs) of English and Turkish speakers (TSs) of English. The purpose is to compare the most salient transition types of the NSs and TSs randomly selected theses introduction, results and discussion, and conclusion sections in the field of ELT between 2010 and 2014. The Keyword in Concordance (KWIC) was used to analyze the data. TM types were analyzed in terms of percentages, frequencies per 1,000 words and they were interpreted by calculating the log-likelihood (LL) value if there was a significant difference in their usage. The results illustrated that the frequencies, and frequencies per 1,000 words of the most salient transition type usage in the sections were different.
\end{abstract}

(C) 2019 JLLS and the Authors - Published by JLLS.

Keywords: Corpus, corpus-based; transition markers (TMs); MA theses; Turkish speakers (TSs) of Engish; native speakers (NSs) of English

\section{Introduction}

A corpus consists of the natural and authentic language and natural texts which are scrupulously collected and organized (Biber, Conrad \& Reppen, 1998). Tognini-Bonelli (2001) emphasized that the texts in a corpus are collected according to some explicit design criteria for a specific purpose from various resources (Charteris, 2004).

It was generally expected that a corpus constituted a standard reference for the language variety which it represented, which presupposed its wide availability to other researchers (McEnery \& Wilson, 2001). Hunston (2002) claimed that corpora reflect natural language and are free of intuition, therefore; their findings can be applied in real life situations. Corpus is a dominant and a frequently used method to study linguistic variation.

A corpus-based approach could bring benefits to learners both in terms of their language awareness and possibly also in their language acquisition (Boulton, 2009, p. 37). An increasing number of corpusbased analyses in language teaching has led language teachers and learners to see empirical descriptions of language use, identify the frequent patterns, and understand the usage of particular forms and words in different registers (Biber \& Reppen, 2002). 


\subsection{Transition Markers}

Transition markers (TMs) are referred as conjunctions (Halliday \& Hasan, 1976), logical connectors (Celce-Murcia \& Larsen-Freeman, 1983), cohesive devices (Schiffrin, 1987) or discourse markers (Fraser, 1999). They are defined as "words or phrases whose function is to show some logical relationship between two or more basic sentences or between a basic sentence and a noun phrase" (Celce-Murcia \& Larsen- Freeman, 1983).

Transitions, as one of the most widely used interactive metadiscourse resources (Burneikaite, 2009), were used to arrange propositions in the text and involve the readers. According to Hyland (2005), TMs were mainly conjunctions and adverbial phrases which help readers interpret pragmatic connections between the steps in an argument by marking additive, contrastive, causative, and sequential steps in the discourse. "Addition" adds elements to the argument and consists of items such as and, furthermore, moreover, in addition, and so on. "Comparison" marks arguments as twofold: similarity, for instance, similarly, likewise, equally, correspondingly, and further or difference, for example, in contrast, however, but, on the contrary, on the other hand, and etc. "Consequence relations" tell readers that either a conclusion is being drawn or justified (e.g., therefore, consequently, in conclusion, and etc.) or an "argument" is being countered, such as admittedly, nevertheless, anyway, in case, of course, and etc. Cohen (1984) mentions two different functions of TMs in that transitions enable the reader to recognize coherence relations and allows the reader to recognize coherence relations which could not be inferred in the absence of a TM. According to Hutchinson (2005), the use of a TM by the writer is optional in some cases whereas in others it is obligatory. Researchers (Halliday \& Hasan, 1976; Schiffrin, 1987; Moser \& Moore, 1995; Kehler, 2002) emphasize that a TM might indicate more than one relation. They point out that since the correspondence between TMs and relations is not one-to-one, the writer has to decide which TM to use to signal a given coherence relation (Knott, 1996, p. 177).

\section{Limitations}

The present study was limited to identifying the types of TMs in the introduction, results and discussion, and conclusion sections of the MA theses written by the native speakers (NSs) of English and Turkish speakers (TSs) of English in the field of ELT between 2010 and 2014.

\section{Methodology}

The TM types were analyzed in terms of frequency and log-likelihood (LL) by means of comparing the data groups. LL calculation was used as the statistical analysis method to indicate the overuse which is referred as the higher frequency of occurrence, and the underuse which is defined as the lower frequency of occurrence. The frequency of a linguistic feature is relevant when compared with other features or across groups. In order to make these comparisons, normalized frequency should be discussed. Relative frequency can be determined by calculating the frequency of the construct per $\mathrm{x}$ number of words. Depending on the item being investigated and the convention in the literature, the researcher might choose to measure the number of instances per 100; 1,000; 10,000 or 1,000,000 words. This is called normalizing. Normalization not only allows researchers to compare linguistic features with one another, it also allows them to compare texts and corpora of differing lengths (Friginal \& Hardy, 2014). This study was designed as twofold: a descriptive study as descriptive statistics gives numerical and graphic procedures to summarize a collection of data in a clear and understandable way 
(Jaggi, 2003, p. 1) and the quantitative research because it is the numerical representation and manipulation of observations for the purpose of describing and explaining the phenomena that those observations reflect (Babbie \& Mouton, 2001). "The obvious benefits of quantitative data are that the numerical form makes comparison easy, data are standardized, visible and amenable to the tests of classical survey statistics" (Cooper \& Branthwaite, 1977 cited by Hart, 1987, p. 29).

\subsection{Instrument( $s)$}

Two different instruments were used to collect the data for this study: a) the MA theses written by the native speakers (NSs) of English in the field of ELT retrieved from ProQuest theses database and b) the Turkish speakers (TSs) of English in the field of ELT retrieved from the higher education council's theses database. Fifty MA theses of the NSs and the TSs (100 theses) were randomly selected between the years 2010 and 2014 to analyze and to compare the types of the TMs in the introduction, results and discussion, and conclusion sections.

\subsection{Data collection and analysis procedures}

Randomly selected 100 (50 TSs and 50 NSs) MA theses were analyzed by the researcher, by picking equally ten theses per each year. The data analyses included computer-supported tools of these two corpora. First of all, the introduction, results and discussion, and conclusion sections were extracted and saved as text files and all the other chapters were excluded from the data. Accordingly, each set of corpus was uploaded to the programme of Keyword in Concordance (KWIC). Liu, Fang and Wei (2014) also reported on a quantitative study of the use of nominalizations across different English varieties which were calculated per 1,000 words in order to make comparisons of texts of diverse lengths possible. In the present study, the TM types were analyzed according to their frequency per 1,000 words. To observe the frequencies of the TM types in two corpora, the identification of TM types in every 1,000 words $(\mathrm{n} / 1,000)$ might give a clearer view of possible differences in total TM type frequency in each corpus. In addition to the frequency analysis, log-likelihood (LL) calculation was also used as the statistical analysis method to indicate the overuse and the underuse of occurrence for the analyzed data. When the expected relative frequency is lower than 5, most tests to measure statistical significance, such as chisquare, are unreliable, except for LL tests (Rayson \& Garside, 2000, cited in Buysse, 2011).

\section{Results}

The transition marker (TM) types; including additive transitions, adversative transitions, sequential transitions, and causal transitions; were analyzed in order to investigate the most salient TM types in the MA theses written by the native speakers (NSs) of English and the Turkish speakers (TSs) of English in the field of ELT. 
Table 1. Overall Frequency and LL Analysis of the TM Types in the MA Theses Written by the NSs of English and the TSs of English

\begin{tabular}{|c|c|c|c|c|}
\hline Types & & TSs & NSs & LL Value \\
\hline & Corpus Size & $1,754,429$ & $1,177,474$ & \\
\hline \multirow[t]{3}{*}{ Additive } & TMs (n) & 22027 & 14846 & $-0.16 *$ \\
\hline & $\mathrm{n}$ per 1,000 & 13 & 13 & \\
\hline & Frequency $(\%)$ & 0.13 & 0.13 & \\
\hline \multirow[t]{3}{*}{ Adversative } & TMs (n) & 2798 & 2632 & $-153.33 *$ \\
\hline & n per 1,000 & 2 & 2 & \\
\hline & Frequency $(\%)$ & 0.02 & 0.02 & \\
\hline \multirow[t]{3}{*}{ Sequential } & TMs (n) & 940 & 695 & $-3.72 *$ \\
\hline & n per 1,000 & 1 & 1 & \\
\hline & Frequency $(\%)$ & 0.01 & 0.01 & \\
\hline \multirow[t]{3}{*}{ Causal } & TMs (n) & 1040 & 810 & $-10.02 *$ \\
\hline & n per 1,000 & 1 & 1 & \\
\hline & Frequency $(\%)$ & 0.01 & 0.01 & \\
\hline
\end{tabular}

Table 1 portrayed the overall frequency and LL analysis of four types of TMs used in the introduction, results, discussion and conclusing sections of MA theses. According to Table 1, among all the TM types, the total usage of the additive transitions for three sections, including; the introduction, results and discussion, and conclusion sections in the theses written by the TSs were 22027 whereas it was 14846 for the NSs. In addition, the additives were used more than the adversative, sequential, and causal transitions by the TSs in the MA theses' three sections. It was revealed that the additive transition usage in all three sections for the TSs of English was higher than those of the NSs of English in their theses. By means of frequency per 1,000 words, the additive transitions for both groups were observed to be the highest (13) in their MA theses. According to the frequency results, both the TSs and the NSs used similar amount of transitions for four types in every 100 words in three sections of their theses. Although the causal and the sequential transitions for both groups displayed the same frequecies $(0.01 \%)$ and proportion of TMs (1) per 1,000 words in all three sections of the MA theses, the sequential transitions contained the lowest number of TMs (695) by the NSs of English.

Besides the overall frequency analysis, to determine the difference between frequencies of both groups, and the significant values of overuse or underuse in the groups, LL calculation was applied. As indicated in Table 1, the LL value of the TM types in the introduction, results and discussion, and conclusion sections of the MA theses between the TSs of English and the NSs of English revealed an underuse which was statistically significant. Moreover, the most significant underuse was observed in the adversative transitions (-153.33) wheras the least LL value was obtained from the additive transitions $(-0.16)$ in the MA theses of both groups. The differences between the TM types in two groups were compared by analyzing their frequencies separately for the mentioned three sections. 
Table 2. Frequency and LL Frequency Analysis of the TM Types for the Introduction Section in the MA Theses Written by the NSs of English and the TSs of English

\begin{tabular}{lcrrrr}
\hline Types & & TSs & NSs & $\begin{array}{l}\text { overuse/underuse } \\
+/-\end{array}$ & LL Frequency \\
\hline Additive & $\mathrm{n}$ & 4528 & 2956 & +0.0 & $+1.37^{*}$ \\
& $\%$ & 84.5 & 85.4 & & \\
& $\mathrm{n} / 1,000$ & 3 & 3 & & $-0.47^{*}$ \\
Adversative & $\mathrm{n}$ & 465 & 328 & +0.0 & \\
& $\%$ & 8.6 & 9.4 & & $+7.93^{*}$ \\
& $\mathrm{n} / 1,000$ & 0.3 & 0.3 & & \\
Sequential & $\mathrm{n}$ & 198 & & & \\
& $\%$ & 3.6 & 94 & +0.0 & $+4.94^{*}$ \\
& $\mathrm{n} / 1,000$ & 0.1 & 2.7 & & \\
Causal & $\mathrm{n}$ & 0.1 & & \\
& $\%$ & 166 & 83 & +0.0 & \\
& $\mathrm{n} / 1,000$ & 0.1 & 2.3 & & \\
\hline
\end{tabular}

Table 2 portrayed the frequency and LL frequency analysis of four types of TMs used in the introduction section of the MA theses. The overuse (+) of TMs in TSs of English was relative to NSs; whereas the underuse (-) of TMs in TSs of English was relative to NSs of English. In addition, the frequency was the percentage of TMs in total of words in groups. As illustrated in Table 2, TSs of English used additive transitions 4528 times with $84.5 \%$ frequency in the introduction section of the MA theses. On the other hand, the most frequently used TM type by the NSs of English was also the additive transitions (2956). In addition, the NSs had the highest percentage (85.4\%) in between the TM types in their theses' introduction section. Moreover, the four TM types for both the TSs and the NSs' theses were similar in number per 1,000 words in the introduction section. Consequently, when the frequencies of the TM types in the theses' introduction section used by the TSs and the NSs were compared, the results indicated that all the transition types were overused by the TSs of English.

As observed in Table 2, the LL values of the TM types used by the TSs of English had indicated an overuse and a significant difference in the additive, the sequential, and the causal transitions. The significant overuses of the sequential, causal, and additive transitions might be a reflection of the TSs more academic writing style in English. However, an underuse was observed in the adversative transitions in the introduction section of the theses written by the TSs. The highest overuse in the TSs' TM types was in sequential transitions with +7.93 and then in causal transitions with +4.94 LL value. The least overuse difference was in the additives with +1.37 LL value. In adversative transitions, the LL frequency revealed an underuse with $-0.47 \mathrm{LL}$ value and a significant difference in the theses' introduction section by the TSs of English. Below were the sample sentences taken from the TSs and the NSs. MATS-INT refers to the introduction section of the MA theses written by the TSs, and MANSINT refers to the introduction section of the MA theses written by the NSs. 


\section{Example 1}

[In Foreign Language Teaching, within 4 basic language skills, reading and listening have been regarded as passive and receptive skills until 1980's whereas speaking and writing have been considered as active and productive skills.]

Extracted from $<$ MATS8-INT $>$

[Although the current study did involve the researcher teaching strategies explicitly, the researcher used strategies such as boldfacing and underlining and grouping the prepositions according to "rules" to help the students understand how to use prepositions.]

Extracted from $<$ MANS46-INT $>$

Table 3. Frequency and LL Frequency Analysis of the TM Types for the Results and Discussion Section in the MA Theses Written by the NSs of English and the TSs of English

\begin{tabular}{llrrll}
\hline Types & & TSs & NSs & $\begin{array}{l}\text { overuse/underuse } \\
+/-\end{array}$ & LL Frequency \\
\hline Additive & $\mathrm{n}$ & 12730 & 7486 & +1 & $+83.22^{*}$ \\
& $\%$ & 81.2 & 74.5 & & \\
& $\mathrm{n} / 1,000$ & 7 & 6 & & \\
Adversative & $\mathrm{n}$ & 1768 & 1567 & +0.0 & $-63.68^{*}$ \\
& $\%$ & 11.2 & 15.6 & & \\
& $\mathrm{n} / 1,000$ & 1 & 1 & & $-12.21^{*}$ \\
Sequential & $\mathrm{n}$ & 476 & 405 & +0.0 & \\
& $\%$ & 3.0 & 4.0 & & $-14.95^{*}$ \\
& $\mathrm{n} / 1,000$ & 0.3 & 0.3 & & \\
Causal & $\mathrm{n}$ & 696 & 581 & -0.6 & \\
& $\%$ & 4.4 & 5.7 & & \\
& $\mathrm{n} / 1,000$ & 0.4 & 1 & & \\
\hline
\end{tabular}

Table 3 portrayed the frequency and LL frequency analysis of four types of TMs used in the results and discussion section of MA theses. In Table 3, TSs of English used additive transitions 12730 times with $81.2 \%$ frequency in the results and discussion section of the MA theses. Moreover, the most frequently used TM type by the NSs was also the additive transitions (7486) with 74.5\%. Furthermore, the TSs had the highest percentage (81.2\%) in between the TM types in the MA theses' results and discussion section.

The frequency of the additive transitions per 1,000 words in the TSs' theses was 7 as illustrated in Table 3. The difference between two groups (7-6) was 1 . In other words, the additive transitions in the results and discussion section of the theses written by the TSs had been used more than the NSs of English. Furthermore, when the frequencies were compared, TM types in these theses' mentioned section were observed that the additive, adversative, and sequential transitions were overused by the TSs. On the contrary, underuse was observed in only the causal transitions (-0.6).

According to Table 3, the LL values of the TM types of the TSs had indicated an overuse with a significant difference in the additive (+83.22) transitions. On the other hand; in the adversative, sequential, and causal transitions revealed an underuse and a significant difference was observed in the 
TSs' results and discussion section of the MA theses. The highest underuse in the TSs' TM types was in adversative transitions with $-63.68 \mathrm{LL}$ value. The least amount of underuse was revealed as -12.21 in the sequential transitions which was statistically significant in the TSs' MA theses' results and discussion section.

The two corpora more significantly overused the additive transitions; but underused the adversatives in the results and discussion section of the MA theses. This could be an explanation for both groups tendency to use additive transitions in their theses. MATS-RD refers to the results and discussion section of the MA theses written by the TSs, and MANS-RD refers to the results and discussion section of the MA theses written by the NSs.

\section{Example 2}

[First opinions about and suggestions for the EPOSTL and also its role in some aspects of teaching are addressed in the themes.]

Extracted from $<$ MATS32-RD $>$

[So during the group work, students might keep silent even though they want to make some comments.]

Extracted from $<$ MANS33-RD $>$

Table 4. Frequency and LL Frequency Analysis of the TM Types for the Conclusion Section in the MA Theses Written by the NSs of English and the TSs of English

\begin{tabular}{llrrrl}
\hline Types & TSs & NSs & $\begin{array}{c}\text { overuse/underuse } \\
+/-\end{array}$ & LL Frequency \\
\hline Additive & $\mathrm{n}$ & 4769 & 4404 & -1.0 & $-231.26^{*}$ \\
& $\%$ & 82.5 & 80.3 & & \\
& $\mathrm{n} / 1,000$ & 3 & 4 & & $-142.80^{*}$ \\
Adversative & $\mathrm{n}$ & 565 & 737 & -0.7 & \\
& $\%$ & 9.7 & 13.4 & & $-0.98^{*}$ \\
& $\mathrm{n} / 1,000$ & 0.3 & 1 & & \\
Sequential & $\mathrm{n}$ & 266 & 196 & +0.0 & \\
& $\%$ & 4.6 & 3.5 & & $-3.20^{*}$ \\
& $\mathrm{n} / 1,000$ & 0.2 & 0.2 & & \\
Causal & $\mathrm{n}$ & 178 & 146 & +0.0 & \\
& $\%$ & 3.0 & 2.6 & & \\
& $\mathrm{n} / 1,000$ & 0.1 & 0.1 & & \\
\hline
\end{tabular}

Table 4 portrayed the frequency and LL frequency analysis of four types of TMs used in the conclusion section of the MA theses. As illustrated in Table 4, the most frequently used TM type in the theses' conclusion section by the TSs was additive transitions with 4769 frequency and for the NSs of English it displayed a frequency of 4404. In addition, the TSs had the highest percentage (82.5\%) in between the TM types of this section. However, the total of the additive transitions used by the NSs (4) per 1,000 words indicated the highest amount than the TSs (3). Similarly, the adversative transition usage in the NSs' (1) theses was also determined to be higher than the TSs (0.3). As the difference between two groups (3-4) was -1.0, the additive transitions in the TSs' MA theses' conclusion section had been observed to be used slightly less than the NSs per 1,000 words. Moreover, it was identified 
that the additive and the adversative transitions were underused by the TSs of English. The results also indicated that both the sequential, and causal transitions were equally overused by the TSs of English $(+0.0)$.

In Table 4, the LL values of the TM types of the TSs of English had indicated an underuse with a significant difference in all of the transition types; including additive, adversative, sequential, and causal transitions. The highest underuse for the TM types was in additive transitions with -231.26 LL value of the TSs' MA theses' conclusion section. The least amount of underuse was revealed as

-0.98 in the sequential transitions which was statistically significant for the TSs' MA theses' conclusion section.

The sample sentences were given to display the underuse in the additive transitions, which were preferred in the theses' conclusion section by the TSs of English which might be a reflection of the NSs of English more formal writing style in English. MATS-CON refers to the conclusion section of the MA theses written by the TSs, and MANS-CON refers to the conclusion section of the MA theses written by the NSs.

Example 3

[In addition, during the evaluation of the papers, we encountered some common interesting mistakes such as the perception of the idiomatic expressions.]

Extracted from $<$ MATS16-CON $>$

[At the same time it could open the discussion about what it means to be a speaker of English in continental Europe and how this relates to a speaker's identity within the global context.]

Extracted from $<$ MANS11-CON $>$

\section{Conclusion}

Transition marker (TM) types are classified as the additive, adversative, sequential, and causal ones that play crucial roles in writing. Regarding these TM types, in the introduction, results and discussion, and conclusion sections of the MA theses written by the TSs and NSs, it could be interpreted that they both used a wide variety of additive transitions since this type was used more than the adversative, sequential, and causal transitions. When the corpus size was taken into account, it was observed that the usage of TSs was higher than of the NSs. In other words, the TSs of English have used high amount of additive transitions in all three sections in their MA theses. Both groups used 0.13 additive transitions in every 100 words in the mentioned sections and the additives they used per 1,000 words were similar in their MA theses in terms of the total transition marker (TM) type usage. The significance of the additive transitions could be in the ability to use language in situationally appropriate ways which maintain discourse cohesiveness and effectiveness in academic writing. According to the overall frequency, the sequential transitions were used the least in their MA theses. The log-likelihood (LL) frequency indicated that the TSs significantly underused all the transition types. Moreover, the adversatives were the most underused transition type in total by them. The reason of the TM type underusage in the corpora could be explained as the NSs have an adequate awareness of the different TM type usage as their mother tongue more than the TSs in their academic texts since they apply the types in their target language.

For the additives, it was clearly observed that the TSs of English used the additives per 100 words less than the NSs of English in the introduction section of the MA theses. However, the TSs used them 
as frequently as the NSs in this section. The additive usage regarding their amount, frequency and usage per 1,000 words were high for the TSs in the results and discussion, and conclusion sections of their MA theses. Among all three sections, the results and discussion section included the most frequent and the most used amount of additive transitions. The TSs had the highest significant overuse in this section because of the high possibility of proportion in the additive transition usage. Nevertheless, the TSs used the additives less than the NSs per 1,000 words in the conclusion section. Furthermore, the highest significant underuse of the additives was due to the frequency interval of both groups. It could be interpreted that the NSs explicitly guided the readers dramatically through their theses by the extensive use of additive transitions.

It is observed that the use of a wide variety of additive transitions was applied by both groups in their MA theses, the reason of this fact could be due to their recognition of the formal usage of the language either as target language or native language. In addition, it could be explained that any type of the TMs and their usage was likely to provide a guide to the reader about the forthcoming information in the MA theses.

According to the usage of the other TM types, namely the adversative, sequential, and causal transitions in the introduction section of the MA theses written by the TSs of English, it was found that the sequential transitions were significantly overused and the adversatives were significantly underused. In the results and discussion, and conclusion sections, the TSs underused the adversative, sequential, and causal transitions. However, the adversatives were significantly underused by the TSs in the mentioned sections.

The results of the present study suggest that the additive transitions used in the MA theses assist the learners in connecting the sentences effectively, organizing the written discourse and the readers in constraining their interpretation of the message. Hence, the significance of additive transitions also underlines their ability, awareness, and preference to use language in situationally appropriate ways which make them maintain discourse cohesiveness, coherence and effectiveness in formal and informal writing.

\section{Discussion}

The awareness of metadiscourse could facilitate comprehension in that the reader approaches to a written text with an awareness of the discourse organization with the presence of certain kinds of resources including specifically transition markers (TMs) with other markers (Aidinlou \& Vafaee, 2012; Camiciottoli, 2003; Intarapraw \& Steffensen, 1995). This study has revealed that explicit teaching of TM types from corpus can be an efficacious alternative to make learners more proficient in their academic writing. With a corpus-based implementation, learners could be provided with several written materials whether authentic or semi-structured/structured ones including various linguistic patterns directly or indirectly presented within samples of numerous markers so that they could individually examine the types of TMs in different contexts.

The learners should be made familiar with the different types of TMs in order to enable to make good variation. Also, in order to ensure that they make use of a wider repertoire of TMs in their academic texts and to prevent their use of limited types and their excessive use, it is also important to introduce the different types of markers with their alternatives apart from the markers that they consistently employ in their academic writings. In addition, providing various TM types with their contextual information could be helpful for learners to better understand the functions of them that occur within their specific contexts. 


\section{References}

Aidinlou, N. A., \& Vafaee, A. (2012). The effect of textual and interpersonal metadiscourse markers on Iranian EFL high school learners' reading comprehension. Journal of Basic and Applied Scientific Research, 2(6), 6210-6214.

Babbie, E. \& Mouton, J. M. (2001). The practice of social research. Cape Town: Oxford University Press.

Biber, D., Conrad, S., \& Reppen, R. (1998). Corpus linguistics: Investigating language structure and use. Cambridge: Cambridge University Press.

Biber, D., \& Reppen, R. (2002). What does frequency have to do with grammar teaching? Studies in Second Language Acquisition, 24, 199-208.

Boulton, A. (2009). Testing the limits of data-driven learning: language proficiency and training. ReCALL, 21(1), 37-54.

Burneikaite, N. (2009). Metadiscoursal connectors in linguistics MA theses in English L1 \& L2. KALBOTYRA, 61(3), 36-50.

Buysse, L. (2011). The business of pragmatics. The case of discourse markers in the speech of students of business English and English linguistics. ITL - International Journal of Applied Linguistics, 161, 10-30.

Camiciottoli, B. C. (2003). Metadiscourse and ESP reading comprehension: An exploratory study. Reading in a Foreign Language, 15(1), 28-44.

Celce-Murcia, M.,\& Larsen-Freeman, D. (1983). The grammar book: An EFLIESL teacher's course. New York: Newbury House.

Charteris, B. J. (2004). Corpus approaches to critical metaphor analysis. Hants: Palgrave-MacMillan.

Cohen, R. (1984). A computational theory of the function of clue words in argument understanding. In Proceedings of the 10th international conference on computational linguistics (pp. 251-258).

Cooper, P.,\& Branthwaite, A. (1977). Qualitative Technology: New Perspectives on Measurement and Meaning through Qualitative Research. 20th Market Research Society Annual Conference, March, 79-92.

Fraser, B. J. (1999). What are discourse markers? Journal of Pragmatics, 31(7), 931-952.

Friginal, E., \& Hardy, J. A. (2014). Corpus-based sociolinguistics: A student guide. New York: Routledge.

Halliday, M. A. K., \& Hasan, R. (1976). Cohesion in English. London: Longman.

Hart, S. (1987). The use of the survey in industrial market research. Journal of Marketing Management, 3(1), 25-38.

Hunston, S. (2002). Corpora in applied linguistics. Cambridge: Cambridge University Press.

Hutchinson, B. (2005). Modelling the similarity of discourse connectives. Proceedings of the 27th Annual Meeting of the Cognitive Science Society (CogSci2005), July 21-23, Italy.

Hyland, K. (2005). Metadiscourse: Exploring interaction in writing. Bodmin: MPG Books.

Intarapraw, P., \& Steffensen, M. S. (1995). The use of metadiscourse in good and poor ESL essays. Journal of Second Language Writing, 4(3), 253-272. 
Jaggi, S. (2003). Descriptive statistics and exploratory data analysis. Indian Agricultural Statistics Research Institute. Retrieved May 24, 2015, from http://iasri.res.in/ebook/EB_SMAR/ebook_pdf\%20files/Manual\%20II/1-DescriptiveStatistics.pdf

Kehler, A. (2002). Coherence, reference, and the theory of grammar. Stanford, CA: CSLI Publications.

Knott, A. (1996). A data-driven methodology for motivating a set of coherence relations. Doctoral dissertation, University of Edinburgh. Retrieved October 27, 2015 from http://www.era.lib.ed.ac.uk/bitstream/1842/583/3/1996-alik.pdf

Liu, Y., Fang, A. C., \& Wei, N. (2014). A Corpus-Based Quantitative Study of Nominalizations across Chinese and British Media English. 28th Pacific Asia Conference on Language, Information and Computation (PACLIC 28), 101-110.

McEnery, T.,\& Wilson, A. (2001). Corpus linguistics: An introduction. Edinburg: Edinburg University Press.

Moser, M.,\& Moore, J. (1995). Using discourse analysis and automatic text generation to study discourse cue usage. In Proceedings of the 1995 Spring Symposium on Empirical Methods in Discourse Interpretation and Generation(pp. 92-98).

Rayson, P.,\& Garside, R. (2000). Comparing corpora using frequency profiling. In proceedings of the workshop on Comparing Corpora, held in conjunction with the 38th annual meeting of the Association for Computational Linguistics (ACL 2000). 1-8 October 2000 (pp. 1-6), Hong Kong.

Schiffrin, D. (1987). Discourse markers. New York: Cambridge University Press.

Tognini-Bonelli, E. (2001). Corpus linguistics at work. Amsterdam/Philadelphia: John Benjamins.

\section{Derlem temelli analiz: Ana dili İngilizce olan ve olmayanların yükseklisans tezlerindeki geçiş belirleyici türleri}

\section{$\ddot{O} z$}

$\mathrm{Bu}$ araştırma anadili İngilizce olan ve olmayanların yükseklisans tezlerindeki geçiş belirleyici türlerini değerlendirmek amacıyla yapılmıştır. İngiliz Dili Eğitimi alanından 2010-2014 yılları arasında her bir gruptan rastgele seçilen yükseklisans tezlerinin giriş, bulgu ve tartışma, ve sonuç bölümlerindeki geçiş belirleyici türlerinin karşılaştırılması amaçlanmaktadır. Veriler Keyword in Concordance (KWIC) Metin Analiz Programı kullanılarak analiz edilmiş̧ir. Geçiş belirleyici türlerinin yüzdelikleri, 1,000 kelimedeki frekansları ve kullanımları bakımından anlamlı bir farkın olup olmadığı Log-likelihood (LL) değerleri hesaplanarak yorumlanmıştır. Çalışma bulguları, her bir grubun yükseklisans tezlerinin incelenen bölümlerindeki geçiş belirleyici türlerinin kullanım yüzdeliklerinin ve 1,000 kelimedeki frekanslarının farklı olduğunu göstermiştir.

Anahtar sözcükler: Derlem, derlem temelli, geçiş belirleyicileri, yükseklisans tezleri, ana dili Türkçe olanlar, ana dili İngilizce olmayanlar 


\section{AUTHOR BIODATA}

Zehra KÖROĞLU completed her Master's and Doctoral Degrees at English Language Teaching programs of Çukurova University. Currently, she is employed as an assistant professor at Çă̆ University, Faculty of Arts and Sciences, the Department of English Language Teaching, Yenice, Tarsus, Mersin, Turkey. 